\title{
Mulheres e Espelhos: a Devastação e o irrepresentável no corpo feminino
}

\author{
Danuza Effegem de Souza, Orcid, $\star$ Giselle Falbo Kosovski ${ }^{\text {Orid }}$
}

\author{
Universidade Federal Fluminense, Niterói, RJ, Brasil
}

\begin{abstract}
Resumo
Este artigo situa a Devastação como operação lógica que remete e contrasta, quanto à incidência e consequências psíquicas, com a operação instauradora do narcisismo no primeiro tempo da constituição subjetiva. Observando a necessidade de reafirmação da imagem no embate arrebatador com o espelho, o trabalho ressalta, com o conto Branca de Neve, algo de estrutural no mal-estar das mulheres em relação à imagem, analisando a delicada relação da madrasta com sua imagem própria refletida pelo espelho falante. Para tanto, relemos Freud, Sobre o narcisismo: uma introdução, e Lacan, O estágio do espelho como formador da função do eu, recorrendo às reflexões psicanalíticas acerca da edificação do corpo para elucidar o processo contínuo de sua construção, que no feminino é reiteradamente confrontado com a falta de um significante (simétrico ao falo) que pudesse alienar o gozo e encerrar a busca por uma representação última para o ser dA mulher.
\end{abstract}

Palavras-chave: Psicanálise; Devastação; beleza; corpo; narcisismo.

\section{Women and mirrors: Devastation and the irrepresentable in the female body}

\section{Abstract}

This article places Devastation as a logical process that highly contrasts, considering occurrence and psychological effects, with the one process which sets narcissism in the first time of Subject Constitution, as described by Freud in Introduction to Narcisism and Lacan in the Mirror Stage. Considering women's necessity to have their image recast, this essay brings the old tale Snow White as a sample of the struggle women have with mirror image to show the structural origin of such discomfort by analyzing the relationship the stepmother has with her own image reflected by the talking mirror. Thus, we have based on psychoanalytical impressions concerning the process of constitution to enlighten the continuous effort of women in assimilating their own image, which, by structure, lacks a name (ideally symmetrical to the phallus) to house female satisfaction and a last word to represent the eventual identity of being a woman.

Keywords: Psychoanalysis; Devastation; beauty; body; narcissism.

Espelho, espelho meu, Há no mundo mulher mais bela do que eu? (GRIMM, 2011)

\section{Introdução}

Este artigo sobre a Devastação feminina articula psicanálise e literatura para abordar a relação singular que as mulheres mantêm com a imagem corporal, da qual elas esperam depreender certa afirmação. Colocamos em destaque a vacilação advinda de uma falha na afirmação da imagem devolvida pelo Outro que pode desvelar um ponto jamais recoberto por identificações. Para isso tomamos como referente a madrasta da jovem personagem protagonista do conto Branca de Neve, deslocando-a do papel fixo de algoz para olharmos também seus tormentos. A madrasta, antagonista, dirige ao espelho um grito de apelo. Será sua imagem ou seu ser que ela necessita ratificar? Uma outra, alhures, representa para ela um perigo: será a mais bela também aquela que encarnará a exceção, dando consistência ao conjunto das mulheres? Mas, que mulher é a mais bela se essa beleza, atributo fugaz, não pode ser possuída em si, mas permanece atrelada a Outro que, movido por seu desejo, faça sua escolha por uma, a mais bela, a eleita? Que lugar resta para ela quando perde a condição de eleita?

\footnotetext{
^Endereço para correspondência: Universidade Federal Fluminense, Instituto de Psicologia, Campus do Gragoatá. Rua Professor Marcos Waldemar de Freitas Reis, $\mathrm{s} / \mathrm{n}^{\circ}$, Bloco N $4^{\circ}$ andar. São Domingos - Niterói, RJ - Brasil. CEP: 24210 201.E-mail: danuzaeffegem@ig.com.br, gifalbo@centroin.com.br
}

O conto Branca de Neve, pertencendo ao domínio público, nos fornece uma versão da mulher atormentada pela própria vaidade, ameaçada em sua existência pela beleza exuberante da enteada que, ao adolescer, passa a encarnar o lugar da rival, da outra mulher. A angústia da madrasta, cristalizada na figura má e cruel, não é, todavia, de todo alheia às mulheres, e está estreitamente ligada ao esforço feminino de construção do corpo tomando o recurso à mascarada. Como nos ensina Fuentes sobre a mascarada:

[...] Joan Rivière soube precisar que a feminilidade não passa de uma máscara, cujo fundamento não repousa no real nem é dado por nenhum instinto. Assim, não há meios de ser mulher senão assumindo um parecer, como revestindo o corpo com um tecido imaginário e simbólico que seja atrativo ao desejo masculino, dando forma À mulher que não existe (FUENTES, 2012, p. 112).

De inúmeras formas, em diferentes culturas, as mulheres frequentemente cobrem-se com adornos, brilhos e ornamentos que justapostos ao corpo pretendem criar uma imagem culturalmente reconhecida como feminina. No Ocidente vemos essas máscaras se multiplicarem, apropriadas pela lógica do mercado e pela sede, por este produzida, de atingir o corpo feminino perfeito. Os contornos dados pela anatomia não resumem em si as insígnias desejadas dentro de cada contexto social: busca-se certo volume, uma textura, alguma exata proporção de medidas. A ciência, não destacada do mercado, também acompanha os investimentos cada vez mais sofisticados em cirurgias plásticas, tratamentos estéticos e fórmulas 
embelezadoras e rejuvenescedoras que visam adequar o corpo a elevados padrões de exigência. Sem negar as influências coercitivas do Capitalismo que há muito nos constitui como seres sociais, neste texto propomos pensar a relação que algumas mulheres tem com a imagem corporal e o que as move na direção dessa busca de afirmação num apelo a outrem.

Ademais, tomando como referência os estudos sobre a Devastação, ${ }^{1}$ pretendemos abordar o sentimento de si experimentado por uma mulher diante do enigma do feminino que a beleza pode vir a contornar e, em contrapartida, os efeitos de sofrimento e desamparo em que a ausência deste suporte imaginário a deixa. Pretendemos também destacar os prejuízos que a excessiva crença nesse recurso imaginário e especular com apelo totalizante pode provocar. Com este objetivo, tomaremos como referências principais os textos Sobre o narcisismo: uma introdução (FREUD, 1914/1996) e O estágio do espelho como formador da função do eu (LACAN, 1949/1998), nos quais respectivamente, Freud e Lacan, cada um em um tempo da psicanálise, discutem a construção do corpo próprio.

Para a formulação desta linha de pensamento tomaremos como balizas duas noções essenciais para a psicanálise, no que se refere ao corpo. A primeira consiste no entendimento de que o corpo não nos é dado naturalmente e não equivale ao organismo. Seus contornos se constituem na relação com o semelhante, em experiências precoces de prazer e desprazer, mediadas pela linguagem. Esta funciona como um tecido significante que vai recobrindo o organismo, humanizando a carne e livrando o sujeito em constituição do desamparo e do despedaçamento, que são experiências originais, erguendo-o da existência real à dimensão simbólica. A segunda é a constituição sexual do sujeito, inicialmente descrita por Freud a partir de uma analogia ao mito de Édipo; nota-se que o próprio Freud reconheceu não conseguir esclarecer o desenvolvimento sexual da menina em mulher satisfatoriamente, ponto de investigação remanescente em seus estudos.

\section{$O$ corpo feminino em questão, ainda}

Desde os primeiros estudos de Freud, esteve em questão o corpo das mulheres histéricas que intrigavam a ciência pelo modo nômade de abrigar sintomas conversivos, metáforas significantes. Da catarse à psicanálise, a concepção de corpo foi sendo desenhada e, desde então, sobre sua plasticidade e subordinação às causas psíquicas muito foi dito. Entretanto, ainda hoje repousa sobre o corpo feminino um enigma quanto a forma de ascender à sexualidade. Tornar-se mulher é um esforço de construção que ficou eternizado nesta fórmula de Simone de Beauvoir (1967), da qual a psicanálise se serve para afirmar que não há natureza feminina: não se nasce mulher, torna-se mulher. Sobre este tema, Brousse (1986) sintetiza em duas vias a orientação que dividia a abordagem da feminilidade para Freud: o filão da castração - do primado do falo e o

\footnotetext{
Devastação, conforme desenvolveremos mais adiante, é o nome dado por Lacan a essa forma de gozo referido ao feminino, formulação que aparece no contexto de seu último ensino e do questionamento sobre o gozo feminino. Os múltiplos sentidos desta palavra, que vão do arrebatamento ao deslumbramento, comunicam a natureza complexa e contraditória, própria do gozo que, enquanto tal, é sofrimento, mas é também satisfação à qual o sujeito adere.
}

filão do real - do não reconhecível. Este último, não recoberto pela linguagem permanece no feminino como um ponto impossível de se fazer representar.

Destacamos que tal impossibilidade de representação se deve ao fato de que há um único significante inscrito no inconsciente no que diz respeito à posição sexual. $\mathrm{O}$ falo é o significante da diferença sexual, diferença que em última instância não pode ser plenamente simbolizada. Para as mulheres, fica posto um problema que é a não correspondência do falo a um órgão no corpo, o que não é sem consequências para sua constituição e posicionamento na partilha sexual. Segundo Jeferson Machado Pinto (2008), o inconsciente é fálico e reconhece apenas o sexo fálico, ignorando, portanto, a diferença sexual. Seguindo Lacan (2008b) em suas formulações sobre o tema em $O$ Seminário: mais, ainda, o autor comenta: "Esse campo, o da mulher, estaria em um mais além e indicaria a posição subjetiva daqueles que operam com o não representável, já que estariam não-totalmente submetidos à inscrição fálica" (PINTO, 2008, p. 96).

Portanto, não há um órgão feminino que corresponda simetricamente ao que o pênis representa para o homem, posto que os órgãos que na mulher se distinguem dos masculinos são os que estão inicialmente referidos à mãe que ela poderá vir a ser (LACAN, 1972-1973/2008). Desde cedo as crianças deduzem e interpretam da observação da genitália feminina a ausência do pênis ou a inferioridade do clitóris, o que tem consequências psíquicas e culturais particulares na forma como as sociedades e os sujeitos percebem e distribuem as funções entre os dois gêneros. Com Lacan (1972-1973/2008, p. 14), vimos que "nada distingue a mulher como ser sexuado senão justamente o sexo" e não obstante, "o sexo da mulher não lhe diz nada, a não ser pelo gozo do corpo".

O texto freudiano de 1925, intitulado Algumas consequências psíquicas da distinção anatômica entre os sexos, contém um resumo e uma revisão do pensamento de Freud sobre as diferenças encontradas na constituição subjetiva de meninos e meninas. Nele, Freud reavalia suas primeiras formulações acerca do desenvolvimento psicológico das mulheres, abandonando a tentativa de estabelecer uma analogia exata para elas com o que se passa com os homens. O editor, em nota introdutória, ressalta a obscuridade em que esteve a vida sexual das mulheres para Freud que, segundo ele, constituiria um dark continent (FREUD, 1932/1996).

Ainda neste artigo, Freud aborda as duas mudanças exigidas à menina, que não encontram paralelo no desenvolvimento do menino: a mudança de seu órgão sexual do clitóris para a vagina e a tomada do pai enquanto objeto de amor em detrimento da mãe, sempre o objeto original. Entretanto, ele traz para o cerne da questão os efeitos distintos da percepção da diferença entre os órgãos sexuais para meninos e meninas. Contrariamente à falta de interesse que a observação da genitália da menina provoca no menino, uma menina, quando vê o pênis, imediatamente se dá conta de que não o tem e quer tê-lo. De acordo com Freud a "inveja do pênis" (FREUD 1932/1996, p. 124) terá consequências de grande abrangência, passando pelo 
sentido de um dano narcísico sofrido, deslocando-se para o ciúme e culminando num afrouxamento da relação afetuosa da menina com seu objeto materno - sendo a mãe responsabilizada pela falta de pênis da filha. Esta decepção com a mãe seria motor da transferência de amor ao pai, levando a menina, para quem a castração é a posição inicial, ao complexo de Édipo.

Freud acrescenta que o mais importante efeito da inveja do pênis, que equivale à descoberta da inferioridade do clitóris é "a pouca tolerância das mulheres à masturbação, o que as faz incapazes de usá-la em circunstâncias nas quais um homem se valeria dela como via de escape, sem qualquer hesitação" (FREUD, 1925/1996, p. 283). A explicação para o fato é que o abandono da sexualidade clitoriana seria precondição para o desenvolvimento da feminilidade. A inveja é uma posição da qual a mulher não consegue declinar facilmente e parece penetrar "através de todos os estratos psicológicos" (FREUD, 1937/1996, p. 270). Paralelamente ao "repúdio da feminilidade" (FREUD, 1937/1996, p. 268), comum aos homens, a inveja do pênis, considerada um resto de masculinidade proveniente da fase fálica, pode vir a contribuir para a construção da feminilidade, quando "o desejo apaziguado de um pênis destina-se a ser convertido no desejo de um bebê e de um marido, que possui um pênis" (FREUD, 1937/1996, p. 268). Nota-se que, em Freud, a feminilidade permanece, de certo modo, elidida pela equivalência fálica: um bebê, um marido.

No conto que estamos tomando como referência, a inveja, enquanto estrutural, aparece voltada à beleza da jovem enteada, que, portanto, estaria ocupando o lugar de filha, evidenciando uma das questões intrínsecas ao acidentado percurso de uma mulher na construção da identidade feminina: a relação mãe-filha. A mãe é primeiro o polo de identificações e, depois, da frustração incontestável e necessária, como nos lembram Diana Corso e Mario Corso:

É importante que a filha possa recolher elementos de identificação com a mãe. Ser como ela em alguns aspectos, mas como um ponto de partida, não de chegada. Perceber a limitação do modelo materno empurra ao trabalho de buscar referenciais e vivências que ampliam o horizonte da vida da filha (CORSO, D.; CORSO, M., 2006, p. 81).

O sentimento antigo de inveja, correlato da inveja do pênis cunhada por Freud, terá muitos efeitos e incursões diferentes, tanto na relação inaugural mãe-filha, como nas formas subsequentes das relações amorosas. Em outros termos, está em jogo a busca por um atributo fálico, que pode assumir inúmeras formas, entre elas a beleza com seu potencial constitutivo e organizador.

Soler (2005) contrapõe a atitude de homens e mulheres em relação ao gozo fálico; identitário e constitutivo para o homem, apenas. Ela sustenta que diante de uma situação de impotência ou fracasso, os homens facilmente recorrem ao exercício do órgão, seja com algum parceiro ou através da masturbação, e esse exercício vale como reafirmação de sua potência e valor. Para uma mulher, em contrapartida, o recurso mais frequente é a sedução, sempre falicizante, via na qual a beleza facilmente ganha lugar central.
As formas como as mulheres - numa posição feminina - cuidam do corpo, valorizando-o, falicizando-o, e, por meio dele, valorizando a si mesmas estão relacionadas a uma tentativa de fazer suplência ao que elas de fato não têm. Soler (2005) em O que Lacan dizia das mulheres caracteriza a posição feminina a partir desta lógica de ser o falo para o Outro. Uma mulher nunca é o falo em si mesma, o que em outras palavras significa consentir em ser tomada como objeto do desejo do outro. Esse modo de tratar o corpo próprio encontra correspondência com a descrição do conceito de narcisismo - o termo foi usado inicialmente por Paul Näcke em 1899 para denotar a atitude de uma pessoa que trata o próprio corpo da mesma forma pela qual o corpo de um objeto sexual é tratado. A este respeito, Freud afirma que "o narcisismo neste sentido não seria uma perversão, mas o complemento libidinal do egoísmo do instinto de autopreservação, que em certa medida, pode justificavelmente ser atribuído a toda criatura viva" (FREUD, 1914/1996, p. 81).

Neste mesmo texto há uma importante referência às mulheres, que desenvolveriam na adolescência um autocontentamento compensatório às restrições sociais impostas (FREUD, 1914/1996). O autor observa que tais mulheres necessitam mais serem amadas do que propriamente amar e que ser amada cumpre a função de aumentar sua autoestima.

A partir dessas referências, podemos pensar que à ausência de um órgão erógeno propriamente dito, as mulheres respondem tomando a própria imagem: o próprio corpo como erógeno. Em $O$ estágio do espelho, Lacan (1949/1998) comenta os efeitos formadores de uma Gestalt sobre o organismo e afirma que eles "se inscrevem numa ordem de identificação homeomórfica que seria abarcada pela questão do sentido da beleza como formadora e como erógena". A beleza, aqui, faz suplência a algo inexistente no corpo, acrescentando ao feminino nu uma espécie de véu. Vestido e nomeado, o objeto feminino ganha existência pelo contorno que o belo provê, arrefecendo o status de Coisa, conforme nos diz Lacan: "O objeto é instaurado numa certa relação com a Coisa que é feita simultaneamente para cingir, para presentificar e para ausentificar" (LACAN, 1960/2008, p. 172).

A sedução alcançada com a arma da beleza faz a atitude feminina oscilar do encantamento à persuasão. Não obstante o caráter ativo envolvido, e muitas vezes elidido, a sedução feminina engendra certa passividade: ser amada. Seus artifícios e máscaras são uma forma ativa de fazer-se tomar como objeto de desejo, objeto a ser escolhido pelo outro sempre outra vez, pois não se trata de uma escolha irrevogável; ao seduzir, uma mulher pretende provocar que outro a cubra com seu desejo, situando-a no lugar de objeto fálico.

Ainda quanto à atitude narcísica das mulheres - tomada por Freud como uma forma de compensação - poderíamos questionar se, com o culto ao corpo, as mulheres não estariam se protegendo do real do qual estão mais próximas e, deste modo, recuperando o sentido de autopreservação que o narcisismo comporta. O feminino, enigmático, escapa a apreensões significantes, furtando- 
-se a representações. Embora as máscaras e adornos pareçam reproduzir e imitar um modelo, o que uma mulher faz do próprio corpo está mais próximo da criação uma vez que inexiste a essência do que seja A Mulher (LACAN, 1973/1993) e, tampouco, a presença de qualquer referência biológica conclusiva.

Lembramos aqui que, para Lacan, todas as coisas criadas pelo homem são da ordem da sublimação (LACAN, 1960/2008), e é no bojo de seu extenso estudo sobre o tema, no Seminário da Ética, que encontramos uma referência preciosa para pensar a constituição do objeto feminino e sua relação com a função narcísica. Neste momento de seu ensino, Lacan (1960/2008) discorre sobre a abordagem do objeto feminino, resgatando o amor cortês para elaborar seu pensamento sobre a sublimação. Esta operação é considerada, por ele, análoga à anamorfose, como um ponto de virada na criação artística. Tal reversão concerne justamente à acessibilidade do feminino. Em outras palavras, "Amor cortês em anamorfose" (LACAN, 1960/2008) nos ajuda a pensar a "Coisa" que no feminino escapa à apreensão, bem como a função de anteparo ao real, desempenhada pela beleza, cingindo ou circunscrevendo a substância primitiva que, segundo Lacan, é um ponto de lesão no nível da imagem.

\section{$O$ amor cortês: a inacessibilidade do feminino}

$\mathrm{Na}$ versão de Lacan, nos primórdios de sua história, a poesia inaugurou uma forma de amor que alterou definitivamente o modo de abordagem do feminino: o amor cortês. Este, que fez emergir a Dama, pode ser lido como um artifício que possibilitou uma espécie de sublimação, esvaziando o objeto feminino da substância real. Lacan chama atenção para os efeitos culturais decisivos que tal poesia produziu pelo modo particular como instaurou a idealização do objeto feminino representado pela Dama, vestida pela beleza. Somente a partir dessa subversão introduzida pelas canções de amor é que se pode dizer, com Lacan, que "Não há possibilidade de cantar a Dama, em sua posição poética, sem o pressuposto de uma barreira que a cerque e isole" (LACAN, 1960/2008, p. 181).

A aura de beleza que adorna o feminino não é equivalente à essência de uma mulher; entretanto, por ser "da natureza do belo permanecer insensível ao ultraje" (LACAN, 1960/2008, p. 284), é que ele pode oferecer-se como anteparo e permitir algum acesso ao real, intangível. Ao mesmo tempo em que permite velar, possibilita certa abordagem do objeto, como explica Lacan (1960/2008, p. 181): “O objeto, nomeadamente aqui o objeto feminino, se introduz pela porta mui singular da privação, da inacessibilidade".

Quanto à função narcísica, Lacan reconhece que permanecera vaga ao longo de sua apresentação sobre a construção cortês e a anamorfose que dera origem ao objeto feminino. Ele explica que a função do espelho, exemplar da estrutura imaginária, se qualifica na relação narcísica, evidenciando que a ideologia do amor cortês possui um caráter profundamente narcísico. Nas palavras de Lacan (1960/2008, p. 183):
O espelho, num dado momento, pode implicar os mecanismos do narcisismo, e nomeadamente, a diminuição destrutiva, agressiva, que reencontraremos em seguida. Mas ele desempenha outro papel_ um papel de limite. Ele é aquilo que não se pode transpor. E a organização da inacessibilidade do objeto é justamente a única coisa da qual ele participa. Mas ele não é o único que participa disso.

$\mathrm{Na}$ arte e na feminilidade o que vislumbramos, com o apoio dos estudos recolhidos, são formas criativas e originais de dar tratamento ao real. Formas de evolvê-lo e emoldurá-lo de maneira singular, que ao mesmo tempo velam e revelam algo da coisa cingida no processo de criação e parcialmente preservada no feminino como núcleo de um gozo inassimilável pelo significante, ou seja, um gozo não recoberto pelas palavras.

Neste sentido, podemos pensar a moldura do espelho como uma margem possível, mas precária, à dispersão intrínseca ao feminino. A imagem especular, que "parece ser o limiar do mundo visível” (LACAN 1949/1998 p. 98) pode ser dotada de eficácia simbólica, estabilizando o corpo numa Gestalt. O que nos permite estabelecer certa analogia entre o infans e uma mulher diante do espelho: enquanto o infans encontra júbilo na edificação da imagem especular e acessa, através dela, uma organização corporal que consiste numa "matriz simbólica" da instância psíquica (eu) que ainda não está formada; uma mulher pode obter satisfação na reafirmação da imagem corporal sustentada em identificações através da imagem que lhe retorna do espelho. Mais adiante, com o estudo da devastação, tal aproximação nos levará, em verdade, a um contraste entre estes dois momentos.

Ainda em relação às identificações em jogo na composição do corpo pela mulher, destacamos que elas podem encontrar apoio nos modelos ofertados pela cultura, pelo mercado, ou ainda ser fruto de criações singulares. Tais modelos podem ser lidos como modos de sustentar a integridade do corpo próprio, de um corpo que se quer inteiro, na tentativa de afastar a ameaça do despedaçamento que arrebataria uma mulher se esta se deixasse capturar pela pura ausência de representação para o seu sexo. Lacan explica: "Pois a forma total do corpo pela qual o sujeito antecipa numa miragem a maturação de sua potência só lhe é dada como Gestalt, isto é numa exterioridade em que decerto essa forma é mais constituinte do que constituída" (LACAN, 1949/1998, p. 95).

Por se tratar de um limiar no campo da representação, é que a imagem interessa sobremaneira aos estudos sobre o feminino. A importância do acesso a uma Gestalt de seu corpo assegura ao sujeito em constituição dois aspectos: a permanência mental do eu e do outro, como nos diz Lacan (1949/1998). Para uma mulher, que não conta sequer com uma indicação da anatomia onde possa ancorar seu gozo feminino, essa Gestalt necessita ser reafirmada, em alguma medida, e assim como no instante formador em que o infans depende de um Outro que o diga e o nomeie, uma mulher também requer do Outro um nome:

[...] por habitar o lado da subjetividade mais exposto ao trato com o real, ela quer encore o traço que a margeie e o 
véu que a vista. Assim, a partir desse trato cotidiano com o impossível, terá mais chances de gozar com o já célebre gozo feminino do que de ser apanhada num horror cujas consequências de estrago podem testemunhar elas mesmas com sua "miséria neurótica" e aqueles que, por uma outra razão, dela dependam ou com ela compartilhem um trecho da viagem da vida (AMIGO, 2007, p. 214).

A feminilidade, segundo Amigo (2007, p. 206), "recorda à estrutura que o império do simbólico do falicismo é não todo" e é por isso que o último ensino de Lacan, menos ligado ao significante e mais afinado com o real, possibilitou avançar sobre este tema.

\section{Devastação: quando o espelho reflete a nudez do irrepresentável}

O apelo da mulher diante do espelho ao qual aludimos no início do texto, portanto, evidencia muito mais a angústia de perder um lugar, do que o júbilo da criança que acessa sua imagem unificada. Antes, o que a assombra é o fantasma do despedaçamento de sua imagem pelo dizer do Outro, ou ainda, pela ausência deste dizer. Analisando contos infantis, Corso, D. e Corso, M. (2006) leem Branca de Neve à luz da psicanálise e em sua relação com os estudos sobre a feminilidade. Eles entendem que "a madrasta convive com uma eterna insegurança a respeito de seus atrativos, não lhe bastava ser bela, sua formosura tinha de ser insuperável" (CORSO, D.; CORSO, M., 2006, p. 80). Em seguida afirmam:

\section{A verdade é que a beleza só existe para um olhar, sem esse reconhecimento ela não faz sentido, por isso o espelho é o complemento necessário da imagem. O olhar no espelho traz sempre uma pergunta e uma resposta. Cada um o contempla tentando se ver "de fora", buscando decifrar o impacto de sua imagem nos olhos dos outros, interrogando como somos vistos" (CORSO, D.; CORSO, M., 2006, p. 80).}

Em Sobre o Narcisismo: uma Introdução, Freud (1914/1996) descreve uma fase de autoerotismo em que o bebê toma seu próprio corpo como objeto, desfruta dele de forma prazerosa, mas ainda não se percebe diferenciado do mundo. O momento ulterior, chamado narcisismo, caracteriza-se pela autopercepção de si como uno, dono de um nome, de um corpo unificado e de uma instância psíquica discriminada: o eu. Ele destaca que entre o autoerotismo e o narcisismo faz-se necessária a presença de um Outro que outorgue, ao sujeito em constituição, sua unidade corporal. Tal unidade se aproxima da Gestalt que suplanta a forma (LACAN, 1949/1998, p. 95) em lugar da percepção inicial de uma dispersão corporal e que se faz a partir de uma imprescindível "nova ação psíquica": a identificação à imagem de si como corpo unificado.

O corpo, em sua dimensão real e sede do gozo, precisa ser reiteradamente apropriado pelo psiquismo do sujeito, inclusive em sua dimensão sexual ao longo da vida e com as transformações do crescimento e envelhecimento, entre outras intercorrências, quer sejam inevitáveis ou eletivas. A experiência princeps, com seu valor de metáfora, será a matriz para as identificações secundárias subsequentes que cumprem a função de normalização libidinal (LACAN, 1949/1998). O impasse que quere- mos destacar neste ensaio é que o corpo feminino, por estrutura, vacila mais facilmente em atingir uma Gestalt, por não encontrar possibilidade de ancoragem em uma identificação satisfatoriamente completa. Assim, a busca indeclinável por um modelo ou traço identificatório pode ser vivida como um tormento, um abismo de sentido.

Em O estágio do espelho (LACAN, 1949/1998) fica demarcada a importância crucial do registro imaginário como mediador entre o corpo orgânico, "real", e a instância corporal simbólica que pela identificação pode se constituir. Retomando o início deste escrito, concluímos que a situação da mulher moderna, pensada no nível da estrutura, de certo modo, já se encontra descrita nas tradicionais histórias orais que nos chegaram através de contos infantis, clamando diante do espelho por uma espécie de validação, ainda que imaginária; e, hoje em dia, buscando e comprando referências, copiando modelos, comprando estilos e marcas.

O espelho pode ser considerado metáfora do olhar do Outro. Para que uma mulher encontre uma forma de se colocar numa posição feminina, é por vezes necessário que ela se sinta abrigada, olhada e margeada pelo desejo de um outro que a singularize, numa relação que se revela constitutiva. Lacan questiona esse enlace amoroso que opera função tão essencial: "o que acontece com o amor, ou seja, com essa imagem de si de que o outro reveste você e que a veste, e que quando desta é desinvestida a deixa?" (LACAN, 1965/2003a, p. 201).

A partir do romance de Marguerite Duras, Lacan descreve o arrebatamento tomando a experiência da personagem Lol V. Stein quando seu corpo deixa de ser continente do olhar do noivo. A este respeito, Fuentes comenta:

A letra do arrebatamento, puro sem sentido, mas plena em sua função de engendrar a passagem da beleza ao corpo da mulher, é o transporte da pura vacuidade de Lol ao corpo da outra mulher, onde um gozo transbordante é então nela localizado (FUENTES, 2012, p. 276)

Do corpo à vacuidade, da beleza à mancha, o arrebatamento ou devastação é uma espécie de desnudamento. É um momento em que o enunciado introjetado no estádio do espelho, que poderia ser traduzido pela expressão "Eu sou isso", sofre uma ameaça ou abalo profundo. E, nessas condições, uma mulher em decorrência das características inerentes ao feminino, pode não dispor de muitos recursos para reestabelecer uma ordenação simbólica ao corpo. Como afirma Marie-Helene Brousse (2004, p. 65): “O arrebatamento é [...] uma perda corporal não simbolizável pelo significante fálico, uma não redução das imagens cativantes à imagem central do corpo, uma não inscrição do corpo no desejo do Outro".

Fuentes relembra o paralelismo de Lacan: ao lado da dor de existir que seria o mal-estar que acomete um sujeito quando o desejo dá lugar à pulsão de morte, haveria o impasse feminino da "dor de inexistir", firmando o sentimento da perda não localizada experimentada por uma mulher que, ao perder o envoltório do amor, perde-se a si mesma, perde o "lastro de sua existência" (FUENTES, 2012, p. 41). 
O termo devastação, tradução para o português do vocábulo francês ravage, aparece pela primeira vez em $O$ Aturdito (LACAN, 1972/2003b), e, conforme a pesquisa de Drummond (2011), é uma palavra ligada ao solo, ao território, à terra. À ela relacionam-se ainda estrago, dano profundo, prejuízo, arrebatamento. Uma terra devastada é uma terra em ruínas, deserta, sem forças, perdida, assolada. Um solo pobre, danificado, impedido de dar frutos, sustentar ou sediar algo.

Uma mulher devastada, portanto, está tomada por um gozo que não pertence ao registro fálico, uma dor que a leva a uma perda de si mesma, uma espécie de apagamento subjetivo, e que, não obstante, satisfaz. Colette Soler (2005) afirma que os efeitos deste eclipse vão da mais leve desorientação até a angústia profunda, passando pela frigidez e todos os graus de extravio e evitação, até o extremo de abolir-se no outro, enquanto sujeito.

A Mulher, sempre outra, não coincide com o corpo feminino, parece estar sempre num outro corpo. Oscilando entre duas posições opostas, pode encarnar a guardiã de um segredo a ser revelado, oferecendo modelos, estereótipos e máscaras a serem copiadas; assim, supostamente, ela seria alvo de amor e devoção. Pode ainda, num extremo oposto, ser colocada como a vilã sem limites que toma para si somente, o brilho desejado por todas, encarnação da madrasta do conto Branca de neve. Neste caso, o ódio the é endereçado por ocupar uma posição de extremo poder, tal como o pai da horda primeva, descrito por Freud (1912-1913/1996). Nas duas posições extremas persiste a crença, devastadora, na consistência ou existência de um significante que, entretanto, precisa sempre ser novamente inventado.

Assim, demandando um significante inexistente no Outro - desamparada pelo simbólico e frustrada em sua demanda de identificação; e, desabrigada pelo recobrimento imaginário, uma mulher se acha confrontada com o real. Nessas condições, ela se aniquila numa devastação, deparando-se com a ausência de substância e, por isso, recobra a angústia da relação mãe e filha não suficientemente mediada pelo falo, correlativa a um momento anterior ao Édipo.

A este sofrimento que se caracteriza pelo transbordar do gozo, contrapõe-se o seu ciframento, operação que impõe recuperações da satisfação sempre parciais. Enquanto o ciframento introduz o sujeito numa vida de relação disposta pela civilização do gozo e, consequentemente, pela possibilidade do acesso ao desejo, o arrebatamento é um instante de desnudamento, que segundo Lacan (1965/2003a, p. 201) estende-se até o indizível da nudez que se insinua ameaçando substituir o próprio corpo. Definido pelo autor como o "lugar do infortúnio" e "limiar entre-duas-mortes", este é um instante em que o feminino como relativamente o concebemos a partir do amor cortês desmorona, e surge em estado de objeto puro (LACAN, $1965 / 2003$ a, p. 201; 202). Lacan (1965/2003a, p. 202) afirma que a função de mancha pertinente a este objeto é "incompatível com a manutenção da imagem narcísica".
Lembrando Freud que indicara que o artista o precedia em sua matéria, Lacan recorre à obra literária de Marguerite Duras, explorando ainda seu processo de criação, para tentar desvendar o enigma do arrebatamento (LACAN, 1965/2003a), como apresentamos anteriormente. A esse respeito Fuentes (2012, p. 279) nos esclarece que:

[...] a figura do arrebatamento em Lol elucida uma relação que as mulheres estabelecem com o real do corpo, que não se esgota na identificação com a imagem própria dada pelo traço unário. Verifica-se que, a impossibilidade de a identificação narcisista recobrir todo o campo do real do corpo revela-se como fato de estrutura.

Ainda de acordo com a autora, "Lacan faz do arrebatamento uma operação lógica subjetiva que estabelece uma relação do sujeito com o corpo, distinta daquela do estágio do espelho que fundamenta a identificação narcisista" (FUENTES, 2012, p. 275). A partir dessas marcações atentamos para o caráter contrário dessas duas operações: Enquanto o infans na situação do espelho passa a reconhecer-se como acolhido no desejo no Outro e pode se apropriar de seu corpo e de sua existência, dando consistência ao Eu; na devastação, inversamente, trata-se da "expulsão do sujeito de seu corpo" (FUENTES, 2012, p. 275), o que se relaciona com o sentimento de inexistência, de vacuidade que caracteriza esta forma particular de apresentação do mal-estar nas mulheres.

A desorganização em que fica mergulhada uma mulher devastada revela como os semblantes e a pregnância do imaginário são estruturantes e denuncia a importância da alienação ao significante e ao Outro na construção do feminino. A ameaça de inexistir é o que impulsiona essa mulher a tomar o corpo, dotado de uma falta, como objeto investido em seu narcisismo, conforme observamos mais frequentemente entre as histéricas. Esse mesmo risco a leva a oferecer o corpo, caracterizando certa passividade, num laço com o outro cuja falta ela anseia suprir.

$\mathrm{O}$ apego à imagem e, consequentemente, ao imaginário - se não o tomarmos apenas como uma defesa - pode ser lido como um trato necessário, um uso do imaginário e de seus semblantes para fazer face ao vazio em que o simbólico deixa uma mulher. Todavia, por trata-se de um semblante, é preciso que uma mulher não esteja totalmente entregue, não tomando o imaginário como referência única para seu ser.

Assim finalizamos esta contribuição preliminar para o estudo da devastação no feminino sob a perspectiva da construção do corpo e suas implicações no que concerne à relação tão comum às mulheres com o espelho; e indicamos que a operação de edificação do corpo em sua articulação com a constituição subjetiva, por suas características formadoras, contrasta com o desnudamento experimentado na devastação. Aqui, resgatamos um pouco do que a experiência psicanalítica já deslindou sobre a constituição do corpo para pensar o sofrimento feminino como um paradigma para se compreender a constituição subjetiva e sexual de uma mulher. Enfatizamos algumas premissas da experiência princeps da constituição do sujeito permeando e desenhando o processo de constituição feminina. Quando 
afirmamos, com a psicanálise, que uma mulher não nasce mulher, mas continuamente se torna mulher, nos interessa indicar, portanto, as múltiplas operações constituintes que possibilitam a invenção e as recriações do corpo admitidas no percurso de um sujeito feminino.

\section{REFERÊNCIAS}

AMIGO, S. Clínica dos fracassos da fantasia. Rio de Janeiro: Companhia de Freud, 2007.

BEAUVOIR, S. O segundo sexo: a experiência da vivida. 2. ed. São Paulo: Difusão Européia do Livro, 1967.

BROUSSE, M. H. L'énigme de la femme. L'âne: Pierre Klossowski, la mutation, v. 28, n. 1, 1986.

BROUSSE, M. H. Uma dificuldade na análise das mulheres: a devastação da relação com a mãe. Rio de Janeiro: J. Zahar, 2004.

CORSO, D. L.; CORSO, M. C. Fadas no divã: psicanálise nas histórias infantis. Porto Alegre: Artmed, 2006.

DRUMMOND, C. Devastação. Opção Lacaniana, v. 2, n. 6, p. 1-14, 2011. Disponível em: http://www.opcaolacaniana.com. br/pdf/numero_6/Devastacao.pdf. Acesso em: 14 dez. 2014.

FREUD, S. Algumas consequências psíquicas da diferença anatômica entre os sexos (1925). Rio de Janeiro: Imago, 1996a. Obras Completas, v. 19.

FREUD, S. Análise terminável e interminável (1937). Rio de Janeiro: Imago, 1996b. Obras completas, v. 23.

FREUD, S. Feminilidade: novas conferências introdutórias sobre psicanálise (1932). Rio de Janeiro: Imago, 1996c. Obras completas, v. 22.

FREUD, S. Sobre o narcisismo: uma introdução (1914). Rio de Janeiro: Imago, 1996d. Obras completas, v. 14.

FREUD, S. Totem e tabu (1912-1913). Rio de Janeiro: Imago, 1996e. Obras completas, v. 8.

FUENTES, M. J. S. As mulheres e seus nomes: Lacan e o feminino. Belo Horizonte: Scriptum, 2012.

GRIMM. Snow white the fairy tales of the brothers Grimm. Cologne: Taschen, 2011.

LACAN, J. Televisão (1973). Rio de Janeiro: J. Zahar, 1993.

LACAN, J. O estágio do espelho como formador da função do eu (1949). In:___ _Escritos. Rio de Janeiro: J. Zahar, 1998. p. 96-103.

LACAN, J. Homenagem a Marguerite Duras (1965). In: 198-205.

Outros Escritos. Rio de Janeiro: J. Zahar, 2003a. p.

LACAN, J. O aturdito (1972). In:___. Outros Escritos. Rio de Janeiro: J. Zahar, 2003b. p. 448-497.

LACAN, J. O seminário: a ética da psicanálise (1960). Rio de Janeiro: J. Zahar, 2008a. livro 7.

LACAN, J. O seminário: mais, ainda (1972-1973). Rio de Janeiro: J. Zahar, 2008b. livro 20.

PINTO, J. M. Psicanálise, feminino, singular. Belo Horizonte: Autêntica, 2008.

SOLER, C. O que Lacan dizia das mulheres. Rio de Janeiro: J. Zahar, 2005. 